\title{
How to Evaluate Woodcock Habitat Management: are Landowners the Answer?
}

ANNA C. BUCKARDT, ${ }^{1,2}$ Department of Wildlife, Fisheries, and Conservation Biology, University of Maine, 5755 Nutting Hall, Orono Maine, 04469-5755

AMBER M. ROTH, Department of Wildlife, Fisheries, and Conservation Biology and School of Forest Resources, University of Maine, 5755 Nutting Hall, Orono Maine, 04469-5755

JESSICA E. LEAHY, School of Forest Resources, University of Maine, 5755 Nutting Hall, Orono Maine, 04469-5755

\begin{abstract}
Loss of young forest, also termed early successional forest, in North America is negatively impacting wildlife populations that rely on this regenerating forest type, especially birds. The Wisconsin Young Forest Partnership (WYFP) targets young forest management efforts to benefit American woodcock (Scolopax minor; hereafter, woodcock) on private lands in Wisconsin. The WYFP uses an adaptive strategy to iteratively evaluate and adjust their habitat management activities. Citizen science can be a valuable evaluation tool in this process. The WYFP aims to develop a citizen science program whereby landowners monitor woodcock in management areas on their properties. We explored the woodcock monitoring preferences and abilities of landowners through questionnaires, interviews, and pilot woodcock surveying to inform the development of a citizen science woodcock monitoring program. Landowners were enthusiastic about participating in woodcock monitoring. When creating a citizen science program for monitoring woodcock it is important to use English units for estimating distance, evaluate landowners' physical ability to hear peenting woodcock, provide in-person monitoring training, and have flexible data submittal options. Development of a successful citizen science program for monitoring woodcock requires balancing researcher goals with participant preferences and abilities.
\end{abstract}

Proceedings of the American Woodcock Symposium 11: 76-84

KEY WORDS: Adaptive management, citizen science, family forest, habitat evaluation, Scolopax minor, singing-ground survey, wildlife monitoring, Wisconsin Young Forest Partnership

Young or early successional forests, defined here as regenerating even-aged forest stands that are generally under 20 years old (Kelley et al. 2008), play an important role for many wildlife species. These cover types were historically created and maintained across the landscape by natural disturbances such as windthrow and fire; human activities such as cropland abandonment and forest harvesting are now the main sources of young forest creation (Trani et al. 2001). Young forests provide a unique vegetation structure, with many dense shrubs, saplings, and herbaceous plants. This dense cover is important to a variety of species (Gilbart 2012) including bobcat (Lynx rufus), smooth green snake (Opheodrys vernalis), New England cottontail
(Sylvilagus transitionalis), and American woodcock (Scolopax minor; hereafter, woodcock). Early successional forest quickly matures and becomes unsuitable for young forest wildlife species unless some form of disturbance occurs to maintain young growth (Trani et al. 2001, Gilbart 2012). Avifauna have been highly impacted by the loss of young forest cover, with population declines of young forest birds paralleling changes in land use and forest succession (Trani et al. 2001).

The Young Forest Project (youngforest.org) was established to address the loss of young forest cover in the eastern United States. Through a collaborative effort by professionals, managers, and private landowners, the Young Forest

1 email: anna.buckardt@maine.edu

2 current affiliation: Iowa Department of Natural Resources, 1436 255th Street, Boone, IA 50036, USA 
Project creates young forest cover to benefit wildlife. Using best management practices, the Young Forest Project creates demonstration areas on public lands and provides resources and recommendations for management on private property. Funding opportunities for wildlife management are made available to private landowners through collaboration with the U.S. Department of Agriculture's Natural Resources Conservation Service, the U.S. Fish and Wildlife Service, the National Fish and Wildlife Foundation, the Ruffed Grouse Society, state agencies, and other partners.

The Wisconsin Young Forest Partnership (WYFP, youngforest.org/WI), a subgroup of the Young Forest Project, focuses its management efforts in north-central Wisconsin, and uses the woodcock and the golden-winged-warbler (Vermivora chrysoptera) as focal species for its young forest management efforts. The Partnership works within an adaptive management framework (Walters 1986) that necessitates an iterative process of evaluation and appropriate adjustment to reach conservation goals for these species. Aceves-Bueno et al. (2015) suggested that insufficient monitoring and lack of stakeholder buy-in are the main reasons that adaptive management systems fail to reach their intended goals. Citizen science-a collaborative effort between volunteers and scientists to collect data-is a potential tool for overcoming those challenges to adaptive management outcomes (Aceves-Bueno et al. 2015).

Although the term "citizen science" may be fairly new (Bonney 1996), the concept of non-professional and amateur scientists collecting quality avian data has a long history. The National Audubon Society's Christmas Bird Count (CBC), started in 1900, is a classic example of volunteers conducting long-term, large-scale bird monitoring. The North American Breeding Bird Survey (BBS, Robbins et al. 1986) is another example, with professional biologists and trained enthusiasts volunteering their time to collect data following a strict scientific protocol. These kinds of volunteer survey efforts contribute to our understanding of North American bird populations and influence management decisions. Citizen science expands the temporal and spatial scales of research by including networks of non-professionals (Dickinson et al. 2010).

Of course, not all science is suitable as citizen science; the protocols and the data collected must be simple enough to be taught fairly quickly to a large number of volunteers. Monitoring that utilizes identification and counting of species and individuals is a popular form of citizen science. Male woodcock have a conspicuous and predictable spring mating display, making them an excellent focal species for citizen science monitoring. Woodcock have also been considered an umbrella species of young forests (Masse et al. 2015), in which managing for woodcock is a strategy that benefits a suite of other wildlife (Kelley et al. 2008). Because they are considered an umbrella spe- cies, woodcock singing-ground surveys are used in part for assessing young forest management for many young forest species (Masse et al. 2015).

Given that much of the WYFP's habitat management is conducted on private properties through collaboration with landowners, the Partnership sees a valuable opportunity to include these landowners in the evaluation stage of their adaptive management framework. The Partnership also recognizes citizen science as a strategy to increase landowners' personal connection and buy-in to young forest management. This inclusion is envisioned as a landowner-based woodcock monitoring program that will help the WYFP evaluate its management efforts, engage landowners with their properties, and provide education on young forest management. Although existing broadscope citizen science programs like eBird (Sullivan et al. 2009) collect data on woodcock, the WYFP needs a more targeted monitoring approach to evaluate habitat management practices implemented by landowners collaborating with the Partnership. The objective of the WYFP is to create a woodcock monitoring program in which landowners survey their properties with a user-friendly protocol based on counting displaying male woodcock in spring, providing feedback on their adaptive management framework.

A successful citizen science monitoring program must accommodate the goals of research as well as the motivations, preferences, and abilities of citizen scientists (Greenwood 2007). To achieve this balance, Greenwood (2007) recommended clearly defining project goals and determining how best to use citizen scientists by understanding their needs, motivations, and limitations. The objective of this research was to gather landowner feedback about woodcock monitoring through interviews and pilot surveys to inform the creation of a citizen science program that suits the needs of both the WYFP and participating landowners.

\section{Study Area}

The focal area of the WYFP's management effort is a 6-county region in north-central Wisconsin. A pilot citizen science program was designed and implemented with family forest landowners in 4 of those counties; Vilas, Oneida, Lincoln, and Langlade. These landowners owned between $\sim 2$ and 16 hectares ( 5 to 40 acres) of land that had either been managed for young forest habitat in the last 5 years or had management planned for the following year. These young forest management areas were either aspen ( $\mathrm{Popu-}$ lus spp.)-dominated forest or alder (Alnus spp.)-dominated shrubland; both are cover types suited for young forest management in the Great Lakes region (Wildlife Management Institute 2009). 


\section{Methods}

\section{DATA COLLECTION}

We used evaluation research methods to capture feedback on the barriers to and opportunities for monitoring woodcock in a citizen science program, and employed quantitative and qualitative techniques and purposive sampling (Miles et al. 2014) to gather feedback from a very specific group of Wisconsin landowners. We designed a questionnaire in 2016 to gather landowner preferences for monitoring woodcock and used these preferences in the development of a pilot woodcock monitoring program. In 2017, we asked landowners to participate in woodcock surveys using this pilot protocol. We used semi-structured interview methods to create a post-survey interview guide that prompted landowners to share specific information about their woodcock monitoring experiences, while giving landowners flexibility in how they shared that information. In this manuscript, we present social science data derived from questionnaires and interviews; we use the term "survey" solely in reference to biological woodcock counts and protocols. This research was conducted with approval from the Protection of Human Subjects Review Board at the University of Maine (2016-04-09, "Exploratory Study of Family Forest Landowner Citizen Science Preferences").

Woodcock monitoring preferences We used an in-person questionnaire (Table 1) to gather landowner preferences for participating in woodcock monitoring on their own properties. Participants answered questions using a 5-point Likert-style scale (Likert 1932) or by selecting from a list of options. During this in-person meeting, we also gathered basic demographic information about the participants through standardized interview questions about age, gender, working status, and education level.

Participant recruitment In May, 2016, we invited landowners or land caregivers (i.e., those family members or friends who tended a particular property in the absence of the landowner) from 21 suitable properties in the study area to participate in this questionnaire. Hereafter, the single term "landowner" includes both actual owners of the land and land caregivers. We spoke with all individuals separately, and in some cases $>1$ landowner associated with each property responded to the questionnaire (e.g., husband and wife, father and son, etc.). Because our research focused on a very specific subset of landowners collaborating with WYFP, we did not intend to conduct a full statistical analysis with this questionnaire, but rather to use landowner responses to inform the creation of a 2017 pilot woodcock monitoring protocol. For that reason, and given the logistical constraints of data collection and the limited pool of properties with completed habitat management through the WYFP, our target sample size was 20 questionnaires.

Pilot woodcock survey In 2017, we created a citizen science woodcock survey protocol and a Midwest Avian Data
Center (data.pointblue.org/partners/mwadc/) online entry portal and database for landowners to monitor displaying male woodcock using young forest management areas on their properties. This protocol was adapted from the American Woodcock Singing-ground Survey of the U.S. Fish and Wildlife Service (Seamans and Rau 2016) and incorporated landowner feedback from the 2016 questionnaire. Woodcock surveys were a 6-min stationary count of all individual peenting (a distinctive vocalization) males detected. Observers recorded the time of first detection and estimated the distance to each peenting male detected. We included a target-diagram on the data sheet to differentiate individual male woodcock (see Appendix A). Observers also recorded environmental data (sunset time, cloud cover, wind speed on the Beaufort scale, and noise level) and metadata (date, observer, point ID). Survey points were pre-determined by the WYFP and located centrally within young forest management areas on participating landowners' property.

In early spring of 2017, landowners who were contacted for in-person questionnaires in 2016 were invited to participate in a woodcock monitoring pilot study on their properties. Prior to the survey date, we provided a detailed written woodcock survey protocol to landowners and instructed them to read the protocol prior to the time of a survey. We intentionally withheld in-person training prior to their first survey experience to remove potential variability in training and to test the effectiveness of our written protocol without additional training. Woodcock surveys were conducted using a side-by-side, but independent, 6-min singing-ground survey by an individual landowner (or small group) paired with a trained technician. Upon completion of side-by-side surveys, the technician interviewed each landowner, asking a short series of questions to gather information on their monitoring experience, their thoughts on the survey protocol, and their willingness to participate in woodcock monitoring in the future. The technicians recorded landowner responses as handwritten notes. During and after interactions with landowner(s), technicians used participant-observation strategies (Spradley 1980) to record notes and observations about their perception of the ability of landowners to conduct woodcock monitoring and any issues landowners appeared to have during the 6-min survey. Before completing interactions with landowners, technicians answered landowner protocol questions and made suggestions for improving performance and survey data quality based on their observations of landowners during the pilot survey.

The number of landowners who participated in pilot monitoring and interviews was limited by the targeted nature of our sampling and our research focus. Additional factors affecting the number of landowners able to participate in 2017 pilot woodcock surveys were the evening timing of surveys, the 20-day duration of the survey sea- 
son, and the availability of 2 field technicians to conduct side-by-side surveys and interviews with landowners. Because of our fairly homogenous sample, we can reasonably expect to reach data saturation - the point where no new themes arise from additional data-at $\sim 12$ interviews (Guest et al. 2006).

\section{Data Analysis}

We summarized landowner responses to the 2016 woodcock monitoring preference questionnaire using simple averaging. We incorporated landowner feedback from the questionnaire into the 2017 pilot woodcock survey protocol and coded field notes from 2017 pilot survey interviews and field observations using elemental and affective methods, then pattern coded (Miles et al. 2014) to find reoccurring themes in the woodcock surveying experiences of landowners. We extracted quotations presented in the results from field notes.

\section{Results}

\section{WOODCOCK MONITORING PREFERENCES (2016)}

Participant demographics Eighteen landowners completed the 2016 questionnaire ( $n=4$ female, $n=14$ male). Participants ranged from 32 to 78 years of age, with an average age of 64 years. Four participants were working, 2 were semi-retired, and 12 were retired. Six participants had an associate's degree or no college degree, 7 had a bachelor's degree, and 5 participants held a master's degree.

Questionnaire results Fifteen of 18 landowners said they would be willing to monitor displaying male woodcock on their own properties for at least 1 to 3 nights each spring (Table 1). Three participants were unwilling to conduct woodcock surveys on their properties. Landowners reported being slightly more likely, on average, to participate in a woodcock survey on their property if they were with a wildlife professional than without one (Table 1). On average, participants thought they would be as likely to conduct a woodcock survey if they had to walk $100 \mathrm{~m}$ into young forest as if they could survey from an easily accessible trail or road, with an average response of 3.8 out of 5 for both scenarios (Table 1). Given the option of estimating distance in meters, feet, or yards, most participants preferred yards (Table 1).

\section{PILOT WOODCOCK SURVEYS (2017)}

Participant demographics Between 25 April and 15 May 2017, 13 individual landowners ( $n=7$ male, $n=6$ female) participated in a side-by-side survey and interview process. These landowners conducted a total of 29 6-min woodcock singing-ground surveys and counted 36 total male woodcock. Twelve participants were $>50$ years old and 1 participant was $<50$ years old. Ten of the landowners who participated in woodcock surveys completed the 2016 questionnaire, whereas 3 had not.

\section{POST-SURVEY INTERVIEWS AND TECHNICIAN OBSERVATIONS}

Landowner confidence and ability After their first experience monitoring woodcock, landowners reported varying confidence in their ability to complete a woodcock survey. Confidence ranged from "nil," "not really confident: I thought we were looking for the birds not listening for them," to "I have a few questions but I understand the concept," to "fairly confident." Landowners expressed that "being able to hear a woodcock and identify it raised my confidence in doing the survey." When asked about their ability to hear woodcock peent calls, 7 landowner monitors thought they could hear peents "reasonably well." The in-person experience of listening for woodcock, not just hearing a recording, proved to be important for landowners. Landowners expressed that they "didn't know what to listen for at first but once [the technician] pointed it out" they could hear it. Listening in the field helped 1 participant realize they experience hearing issues that might affect their ability to survey; "I could hear them fine but direction takes work because I have one bad ear." Six landowners reported low confidence in being able to hearing woodcock peents: "Question mark there, my hearing is not the best," "I heard it when we got close to it but not again," "losing confidence because my ears are ringing and I'm straining to hear." Trained technicians participating in side-by-side pilot surveys with landowners were confident that 6 of 13 landowners were physically able to hear woodcock peent calls well enough to conduct a survey on their own ( $n=4$ female, $n=2$ male).

Landowners were asked which parts of the survey were most difficult for them. Three landowners reported having difficulty with "estimating distance" to a peenting woodcock. Others said "hearing and identification" of woodcock were issues and "knowing what to listen for," and "too many other calls, it's hard to focus on the woodcock" were causes for that difficulty. One landowner mentioned the difficulty of "transferring $15 \mathrm{mph}$ wind speed to the $0-5$ [Beaufort] scale." Technicians observed several cases of landowners recording wind speeds in miles/hour instead of in the Beaufort scale values described on the data sheet.

Landowner impressions of survey protocol Overall, landowners found the survey protocol easy to follow: "on a scale of 1 to 10, 7," "that was easy," "real good, excellent," "it was fine." Several landowners expressed ease in following the protocol overall but had "some specific questions" about parts of the protocol. One landowner thought, "it was a lot to read, lots of words, but straightforward." Six landowners offered specific suggestions for improving the survey protocol. Those suggestions included: 1) making it shorter-"break up the words, make an easy table, the info is good just too long to read;" 2) clarifying the purpose of the distance diagram on the data sheet- "the distance map...how are we supposed to mark it?" and "clarifying 
that the target diagram is to help with the number of individual birds;" and 3) making the web link to the woodcock sound easier to find - "biggest thing was what do I listen for? It doesn't sound like a peent to me." Suggestions for improving the data sheet included "larger print on the datasheet even if it took 2 pages," and "written instructions on a second sheet to bring into the field" to help remind them of survey protocol while they were surveying.

Other general suggestions by landowners for improving their monitoring experience included: "making the

Table 1. In 2016, 18 Wisconsin landowners implementing young forest management on their properties were asked about their American woodcock (AMWO) monitoring preferences. Participant responses to an in-person questionnaire addressing landowner preferences for woodcock monitoring are shown here. Q1 and Q6 were multiple choice, and Q2-Q5 were answered on a 5-point Likert-style scale where 1 represented very unlikely and 5 represented very likely.

\section{Distribution of Responses by Question}

\begin{tabular}{|c|c|c|c|c|c|c|}
\hline Response & $Q_{1}{ }^{a}$ & $\mathbf{Q 2}^{\mathbf{b}}$ & $\mathrm{Q}^{\mathrm{c}}$ & $\mathrm{Q}_{4}{ }^{\mathrm{d}}$ & $\mathrm{Q}^{\mathrm{e}}$ & $Q^{f}{ }^{f}$ \\
\hline mean response & $\mathrm{N} / \mathrm{A}$ & 3.9 & $3 \cdot 3$ & 3.8 & 3.8 & $\mathrm{~N} / \mathrm{A}$ \\
\hline mode response & $1-3$ days & 5 & 5 & 5 & 4 & yards \\
\hline o nights & 3 & & & & & \\
\hline $1-3$ nights & 8 & & & & & \\
\hline $3-5$ nights & 7 & & & & & \\
\hline 1, very unlikely & & 2 & 3 & 3 & 1 & \\
\hline 2, unlikely & & 0 & 3 & 0 & 1 & \\
\hline 3 , neutral & & 3 & 3 & 4 & 4 & \\
\hline 4, likely & & 5 & 3 & 2 & 7 & \\
\hline 5, very likely & & 8 & 6 & 9 & 5 & \\
\hline meters & & & & & & 1 \\
\hline feet & & & & & & 3 \\
\hline yards & & & & & & 10 \\
\hline feet or yards & & & & & & 3 \\
\hline any unit & & & & & & 1 \\
\hline \multicolumn{7}{|c|}{$\begin{array}{l}\text { a How many nights would you be willing to dedicate to AMWO surveys } \\
\text { between April } 25 \text { and May 15th? }\end{array}$} \\
\hline \multicolumn{7}{|c|}{$\begin{array}{l}\text { b How likely are you to participate in an AMWO survey on your own property } \\
\text { if you are with a wildlife professional? }\end{array}$} \\
\hline \multicolumn{7}{|c|}{$\begin{array}{l}\text { 'How likely are you to conduct an AMWO survey on your property without } \\
\text { a wildlife professional (you can conduct the survey with family members, } \\
\text { friends, neighbors, etc.)? }\end{array}$} \\
\hline \multirow{2}{*}{\multicolumn{7}{|c|}{$\begin{array}{l}\text { d How likely are you to conduct an AMWO survey from a road or trail, where it } \\
\text { is fairly accessible? } \\
\text { e How likely are you to conduct an AMWO survey } 100 \text { meters (or } 328 \mathrm{ft} \text { or } \\
109 \text { yards) off a trail or road, into the habitat? }\end{array}$}} \\
\hline & & & & & & \\
\hline \multicolumn{7}{|c|}{$\begin{array}{l}\text { f Which system and unit of measurement are you most comfortable using to } \\
\text { estimate distance, meters, feet, or yards? }\end{array}$} \\
\hline
\end{tabular}

time commitment required clearer to landowners," "before we went out, play the vocalization" as a "refresher of what noise to listen for," and "go through the form before the survey and point out the difference boxes and lines and what info goes where."

Future participation in monitoring Landowners were asked if they would have hesitation in conducting the same woodcock survey on their own in the future. None of the landowners reported disinterest in participating again in the future. Their responses fit into 3 categories: 1 ) no hesitation, 2) wanting more practice, and 3) hesitation because of hearing. Those who expressed no hesitation felt that they would "give it a shot," they were "happy to" because "it was fun!" and said they might invite company: "I'm gonna do it with my kids." Several thought that if they "had more practice [they] would do it again, 6 minutes [the time it takes to monitor one survey point] is not a big commitment." Others were "not ready to do it on my own yet," but implied with more practice they might be interested. The final group of landowners was hesitant only because of their hearing; "yeah, I would do it. Worst thing would be listening for them. I'd bring someone along," and "The hearing issue, I don't want to give you bad data, otherwise no [hesitation]."

Landowner preferences for data submittal Eleven participants said they would be willing to enter their data online, whereas 2 reported a preference to mail in their data sheets with 1 saying "I don't have a computer at home." Of the 11 landowners willing to enter data online, 5 registered to enter their data online and 3 took the step of entering data online. Those who entered data did so accurately.

\section{Discussion}

The WYFP is working to create a monitoring program in which landowners conduct valuable woodcock surveys and that offers education and engagement that help landowners better understand the young forest management outcomes on their properties. From our perspective as researchers, the woodcock data collected must be valid and useful to the specific goal of assessing the impact of WYFP's management efforts. Using citizen science monitoring is a valuable strategy for evaluating and updating management efforts in an adaptive management framework (AcevesBueno 2015). Collaborating with citizen scientists can overcome some of the financial and logistic challenges of traditional research by expanding the geographic and temporal scope of research and increasing access to private lands (Dickinson 
et al. 2010). Leaders of the WYFP appreciate the ecological importance and management implications of monitoring and evaluating efforts on private lands (Gibbs et al. 1999) but have limited financial means to do so. They also appreciate the social benefits of including stakeholders in the adaptive management process (Larson et al. 2013, AcevesBueno 2015). The citizen science program they envision creates a compromise between the lower cost and potentially lower skill level of landowners conducting surveys and the benefit of educating and engaging landowners through their participation. Although paid technicians likely provide higher quality ecological data, the cost of their time, along with the added challenge of accessing private lands across a large geographic area, makes them an unrealistic option within the WYFP budget. By taking the time to understand the views, preferences, and limitations of Wisconsin landowners (Greenwood 2007), the WYFP is increasing the likelihood of creating a scientifically rigorous, user-friendly, and engaging woodcock monitoring program that meets its monitoring and outreach objectives.

Other researchers highlight the importance of understanding volunteers (Weston et al. 2003, Greenwood 2007) and creating a sense of community among volunteers and researchers (West and Pateman 2016). Clearly explaining why the research is important and why particular variables are of interest increases volunteer interest and dedication to the project (Rotenberg et al. 2012). In our 2017 pilot survey protocol, we explained how landowner-collected data would be used, and the personal benefits of participating in monitoring: "The data you collect will help the Wisconsin Young Forest Partnership and other natural resource organizations and agencies assess the effectiveness of young forest management strategies, such as those implemented on your property. This will also give you, the observer, an opportunity to learn more about your property and the wildlife it supports." In-person trainings are an important strategy for increasing volunteer confidence in protocols and help increase data consistency and quality (Newman et al. 2003, Gallo and Waitt 2011, Rotenberg et al. 2012). Our post-survey interviews reflected this need for in-person training, with landowners expressing a desire for additional direction prior to surveying, and several indicating that more practice or training would help encourage them to participate in the future. Reporting findings back to volunteers (Hobbs and White 2012) and giving opportunities for volunteers to provide feedback (West and Pateman 2016) also improves the volunteer experience and longterm interest in the research. The WYFP plans to create an annual report, summarizing woodcock monitoring efforts and findings, for landowners. We encouraged communication and welcomed landowner questions and feedback by clearly listing organizer contact information on our pilot survey protocol.

\section{RECOMMENDATIONS FOR LANDOWNER WOODCOCK MONITORING}

One important way to improve the consistency and quality of woodcock monitoring data is to provide in-person training for all participants (Table 2). We intentionally withheld pre-survey training prior to the pilot monitoring project and only provided landowners with a written protocol before attempting their first survey. Trained technicians conducting surveys alongside landowners were not confident in the consistency and quality of the data landowners were collecting after reading the written protocol alone. A possible supplement or alternative to in-person training would be to create training videos that remind landowners what to listen for and how to complete the data sheet. In a Massachusetts study, participants trained with videos were found to be as successful at identifying invasive plants as those who received in-person training, and better than those who received text and photo-based training (Starr et al. 2014). Based on participant feedback and technician observations, we concluded that gaining experience through practice is key (Table 2). Several landowners conducted pilot surveys on 2 separate occasions. Anecdotally, these landowners seemed more confident and performed better during their second woodcock monitoring experience than their first.

Dickinson et al. (2010) point out the importance of understanding and accounting for observer skill level and experience and recognizing "first-year" effects, with the survey skills of new observers improving over time. The BBS excludes surveys from first-year observers in their population analyses because first-time observer data has been found to artificially increase population trend estimates, as their bird detections increase with survey practice (Kendall et al. 1996). The North American Amphibian Monitoring Program (Weir 2005) requires its volunteers to take a frog call identification quiz (http://www.pwrc. usgs.gov/Frogquiz/) and score above a set threshold before they can participate in monitoring. Birder Certification Online (http://birdcertification.org/) is a similar tool that tests visual and auditory bird identification. Programs like the BBS and CBC provide learning tools and identification resources but do not require a formal evaluation of skill level before volunteers conduct surveys.

Possibly the most important aspect of creating a successful woodcock monitoring program to produce quality scientific data is to make sure that landowners who are collecting data are physically capable of hearing a peenting woodcock from $\geq 100 \mathrm{~m}$ (Table 2). The landowners in the potential pool of citizen scientists for the WYFP are largely retired and over the age of 50. Of the 13 landowners who participated in pilot surveys, 6 self-reported having issues hearing peent calls, and technicians felt that 7 were not able to hear woodcock peents well enough to survey on their own. Farmer et al. (2014) found that hearing and 
other age-related factors are a source of error in bird monitoring that could bias management decisions. To remove this bias, it is important to have some form of standardized evaluation of participants' abilities to hear peenting male woodcock well enough to conduct a survey on their own, and to continue these hearing checks through time as they continue to collect data in consecutive years. Bergh and Andersen (this volume, Detection probability and occupancy of American woodcock during Singing-Ground Surveys) accounted for differences in survey ability by incorporating the effect of individual observers on woodcock detection.

Developing a standardized evaluation for hearing ability and identifying woodcock will be necessary for the WYFP to meet its goal of creating a citizen science program that produces reliable data. If there is no formal evaluation of hearing ability, there will be no way to separate surveys in which woodcock are absent or undetectable from those in which landowners are physically unable to detect them. Data with such uncertainty cannot be used for making sound management decisions. If landowners are unable to hear woodcock peents to a testable standard, encouraging partner or small group monitoring, where someone who is able to hear well enough partners with someone unable to adequately hear peenting woodcock, is a more inclusive

Table 2. Recommendations for creating a landowner American woodcock monitoring program on private lands. These recommendations are based on landowner feedback from questionnaires, interviews, and pilot surveys conducted in north-central Wisconsin in 2016 and 2017.

\section{Recommendations for Landowner Woodcock Monitoring \\ 1. Provide in-person and/or video-based survey training for landowners. \\ 2. Standardize annual evaluation of landowners' ability to hear peenting woodcock from at least $100 \mathrm{~m}$ away. \\ 3. Encourage pre-survey practice, as this is import- ant for landowner confidence and data reliability. \\ 4. Consider how first-time observer effects may impact data reliability and quality when conduct- ing and interpreting data analysis. \\ 5. Provide flexible data submittal channels, includ- ing both online and paper forms. \\ 6. Require submission of all hard copy data sheets to increase likelihood of receiving all survey data. \\ 7. Develop a network of non-landowner volunteers to survey at properties where landowners are unable or unwilling to survey but willing to grant access for monitoring.}

option than barring a landowner from monitoring altogether. The partner monitor(s) could be a family member or friend who is trained to monitor, or even possibly an unassociated trained volunteer who would be granted access to the property for monitoring. This volunteer access strategy could also be used for properties where landowners are uninterested or unable to conduct surveys themselves but are willing to allow access to their properties for someone else to conduct woodcock surveys (Table 2).

Flexibility with data reporting methods also appeared important in our pilot project (Table 2). There are many benefits to using online databases in which landowners can enter their observations in a centralized location for storage, organization, analysis, and exploration (Newman et al. 2010, Dickinson et al. 2012, Miyazaki et al. 2015). However, given the older age demographic of the landowners who may monitor woodcock, an option for returning hard-copy data seems necessary to accommodate all computer skill levels and those who may not have access to computers. Given the low rate of online reporting by monitors in our pilot study, monitoring programs may benefit from making the return of hard-copy datasheets a standard practice to ensure that all data collected is received (Table 2). Although we do not fully understand the discrepancy between the 11 landowners willing to enter online data and the 5 who actually did, training may play a role. In our pilot study, landowners were given written instructions for online submission, but we provided no in-person training or demonstration. Including explicit training for data submission procedures and periodic reminders may increase online reporting by landowners.

\section{FUTURE STEPS FOR WYFP LANDOWNER WOODCOCK MONITORING}

The WYFP is currently reviewing its citizen science monitoring objective, using the information gathered in this study, to better align the ability and interest of the landowners with the Partnership's scientific interests. This objective will be evaluated again in the future to determine how well the program is reaching its intended research and participant goals. The next steps will include an update of the survey protocol to reflect the suggestions made by pilot study landowners and the revised program objective. Developing training and outreach materials that 1) clearly and concisely lay out the goals and importance of monitoring, 2) explain the purpose and value of the citizen scientist to the Partnership's evaluation objective, and 3) educate and engage landowners will help maintain landowner interest and participation in woodcock monitoring. Making protocols and training materials available in a centralized and user-friendly online location on the WYFP's website will enhance usability of the program. Systems for clear and simple communication and annual reporting back to landowners, as well as a channel for gathering 
landowner feedback into the future, will be developed to increase the longevity of participation by landowners.

Revising the WYFP's evaluation objective to be consistent with landowner needs and abilities is key to the successful launch and sustainability of a citizen science-based woodcock monitoring program. The strategies and recommendations from this research will help other land managers decide if a citizen science program is right for them as they create wildlife monitoring and habitat management evaluation programs in the future.

\section{Acknowledgments}

This research was made possible by the Maine Agricultural and Forest Experiment Station, a U.S. Fish and Wildlife Service Webless Migratory Game Bird Program grant, and additional funds from the Wisconsin Sustainable Forestry Initiative's Implementation Committee. Point Blue Conservation Science, L. Salas, and K. Koch assisted in creating and hosting an online entry portal and database for our pilot woodcock monitoring program. Woodcock survey data sheets were adapted from a design by D. McNeil. We would like to thank the landowners who provided access to their properties and valuable feedback during this woodcock monitoring investigation. A big thank you, also, to the technicians who helped with side-by-side monitoring and landowner interviews.

\section{Literature Cited}

Aceves-Bueno, E., A.S. Adeleye, D. Bradley, W.T. Brandt, P. Callery, M. Feraud, K.L. Garner, R. Gentry, Y. Huang, I. McCullough, I. Pearlman, S.A. Sutherland, W. Wilkinson, Y. Yang, T. Zink, S.E. Sanderson, and C. Tague. 2015. Citizen science as an approach for overcoming insufficient monitoring and inadequate stakeholder buy-in in adaptive management: criteria and evidence. Ecosystems 18:493-506.

Bergh, S.M., and D.E. Andersen. Detection probability and occupancy of American woodcock during singing-ground surveys. Pages 200-208 in D.G. Krementz, D.E. Andersen, and T.R. Cooper, Editors. Proceedings of the Eleventh American Woodcock Symposium. University of Minnesota Libraries Publishing, Minneapolis, Minnesota, USA.

Bonney, R. 1996. Citizen science: a Lab tradition. Living Bird 15(4):7-15.

Dickinson, J.L., B. Zuckerberg, and D.N. Bonter. 2010. Citizen science as an ecological research tool: challenges and benefits. Annual Review of Ecology, Evolution, and Systematics 41:49-72.

Farmer, R.G., M.L. Leonard, J.E. Mills Flemming, and S.C. Anderson. 2014. Observer aging and long-term avian survey data quality. Ecology and Evolution 4:2563-2576.

Gallo, T., and D. Waitt. 2011. Creating a successful citizen science model to detect and report invasive species. BioScience 61:459-465.

Gibbs, J.P., H.L. Snell, and C.E. Causton. 1999. Effective monitoring for adaptive wildlife management: lessons from the Galápagos Islands. The Journal of Wildlife Management 63:1055-1065.

Gilbart, M. 2012. Under cover: wildlife of shrublands and young forest. Wildlife Management Institute, Cabot, Vermont, USA

Greenwood, J.J.D. 2007. Citizens, science and bird conservation. Journal of Ornithology 148:S77-S124.
Guest, G., A. Bunce, and L. Johnson. 2006. How many interviews are enough? An experiment with data saturation and variability. Field Methods 18:59-82.

Hobbs, S.J. and P.C.L. White. 2012. Motivations and barriers in relation to community participation in biodiversity recording. Journal of Natural Conservation 20:364-373.

Kelley, J.R. Jr., S. Williamson, and T.R. Cooper. 2008. American woodcock conservation plan: a summary of and recommendations for woodcock conservation in North America. Complied by the Woodcock Task Force, Migratory Shore and Upland Game Bird Working Group, Association of Fish and Wildlife Agencies. Wildlife Management Institute, Washington, D.C., USA.

Kendall, W.L., B.G. Peterjohn, and J.R. Sauer. 1996. First-time observer effects in the North American Breeding Bird Survey. The Auk 113:823-829.

Larson, A.J., R. Travis Belote, M.A. Williamson, and G.H. Aplet. 2013. Making monitoring count: project design for active adaptive management. Journal of Forestry 111:348-356.

Likert, R. 1932. A technique for the measurement of attitudes. Archives of Psychology 22:1-55.

Masse, R.J., B.C. Tefft, and S.R. McWilliams. 2015. Higher bird abundance and diversity where American woodcock sing: fringe benefits of managing forests for woodcock. The Journal of Wildlife Management 79:1378-1384.

Miles, M.B., A.M. Huberman, and J. Saldaña. 2014. Qualitative data analysis: a methods sourcebook. Third Edition. SAGE Publications, Inc, Thousand Oaks, California, USA.

Miyazaki, Y., A. Murase, M. Shiina, R. Masui, and H. Senou. 2015. Integrating and utilizing citizen biodiversity data on the web for science: an example of a rare triggerfish hybrid image provided by a sport fisherman. Journal of Coastal Research 31:1035-1039.

Newman, C., C.D. Buesching, and D.W. Macdonald. 2003. Validating mammal monitoring methods and assessing the performance of volunteers in wildlife conservation-"sed quis custodiet ipsos custodies?” Biological Conservation 113:189-197.

Newman, G., D. Zimmerman, A. Crall, M. Laituri, J. Graham, and L. Stapel. 2010. User-friendly web mapping: lessons from a citizen science website. International Journal of Geographic Information Science 24:1851-1869.

Robbins, C.S., D Bystrak, and P.H. Geissler. 1986. The Breeding Bird Survey: its first fifteen years, 1965-1979. U.S. Fish and Wildlife Service Resource Publication No. 157.

Rotenberg, J.A., L.M. Barnhill, J.M. Meyers, and D. Demarest. 2012. Painted bunting conservation: traditional monitoring meets citizen science. Pages 125-137 in C.A. Lepczyk and P.S. Warren, editors. Urban bird ecology and conservation. University of California Press, Berkeley, USA.

Seamans, M.E., and R.D. Rau. 2016. American woodcock population status, 2016. U.S. Fish and Wildlife Service, Laurel, Maryland, USA.

Spradley, J.P. 1980. Participant observation. Holt, Rinehart and Winston Inc., Orlando, Florida, USA.

Starr J., C.M. Schweik, N. Bush, L. Fletcher, J. Finn, J Fisher, and C.T. Bargeron. 2014. Lights, camera...citizen science: assessing the effectiveness of smartphone-based video training in invasive plant identification. PLoS One 9(11):e111433. doi:10.1371/journal. pone.0111433

Sullivan, B.L., C.L. Wood, M.J. Iliff, R.E. Bonney, D. Fink, and S. Kelling. 2009. eBird: a citizen-based bird observation network in the biological sciences. Biological Conservation 142: 2282-2292.

Trani, M.K., R.T. Brooks, T.L. Schmidt, V.A. Rudis, and C.M. Gabbard. 2001. Patterns and trends of early successional forests in the Eastern United States. Wildlife Society Bulletin 29:413-424.

Walters, C.J. 1986. Adaptive management of renewable resources. MacMillan, New York, USA. 
Weir, L.A. and M.J. Mossman. 2005. North American Amphibian Monitoring Program (NAAMP). Pages 307-313 in M.J. Lannoo, editor. Amphibian declines: conservation status of United States species. University of California Press, Berkeley, USA.

West, S. and R. Pateman. 2016. Recruiting and retaining participants in citizen science: what can be learned from the volunteering literature? Citizen Science: Theory and Practice. 1(2):15.
Weston, M., M. Fendley, R. Jewell, M. Satchell, and C. Tzaros. 2003. Volunteers in bird conservation: insights from the Australian Threatened Bird Network. Ecological Management and Restoration. 4:205-211.

Wildlife Management Institute. 2009. Best management practices for woodcock and associated bird species: upper Great Lakes woodcock and young forest initiative. youngforest.org/documents> Accessed 10 Aug 2017.

UMaine 2017 American Woodcock Landowner Data Sheet

\begin{tabular}{|c|c|c|c|c|c|c|c|}
\hline \multicolumn{2}{|c|}{ Property Owner/Site: } & & Point ID: & Month: & & ay: & Year: \\
\hline State: & \multicolumn{3}{|l|}{ County: } & \multicolumn{2}{|c|}{ Visit (circle): 12} & \multicolumn{2}{|c|}{ Observer: } \\
\hline \multicolumn{2}{|c|}{$\begin{array}{l}\text { Sunset }+ \text { Sky Cond Addition }= \\
\text { Earliest Possible Start time: } \\
\quad: \overline{<\text { Sunset }><15 \text { or } 22 \text { min }>}\end{array}$} & \multicolumn{2}{|c|}{ 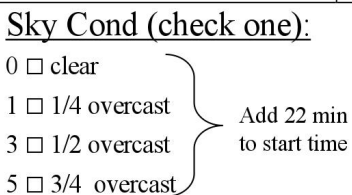 } & $\begin{array}{l}\text { Estimated } \\
\text { Temperature: }\end{array}$ & \multirow{2}{*}{\multicolumn{3}{|c|}{$\begin{array}{l}\text { none } \square \text { no effect on count } \\
\text { low } \square \text { slightly affecting count } \\
\text { moderate } \square \text { moderately affecting cou } \\
\text { heavy } \square \text { seriously affecting count } \\
\text { Source(s) of disturbance: } \\
\text { i.e.: frogs, traffic }\end{array}$}} \\
\hline \multicolumn{2}{|c|}{$\begin{array}{c}\text { This survey began at: } \\
: \quad 1 \mathrm{pm}\end{array}$} & \multicolumn{2}{|c|}{$\begin{array}{l}5 \square 3 / 4 \text { overcast } \\
7 \square>3 / 4 \text { overcast } \quad-\text { Add } 15 \mathrm{~min}\end{array}$} & Wind (0-5): & & & \\
\hline Precip: & fo & & mist $\square$ & sht rain $\square$ & \multicolumn{2}{|c|}{ heavy rain } & snow \\
\hline
\end{tabular}

Wind: $0=$ smoke vertical, $1=$ smk drift, $2=$ wind on face, $3=$ twg constant motion, $4=$ sm branches move, $5=$ trees sway

Disturbance Examples: None = e.g., crow occasionally calling; Low = e.g., distant traffic noise; Moderate = e.g., intermittent traffic noise, soft chorus of spring peepers; Heavy = e.g., continuous traffic, loud chorus of peepers

\begin{tabular}{|c|c|c|c|c|c|c|}
\hline \multirow[t]{2}{*}{ Bird ID } & \multirow{2}{*}{$\begin{array}{l}\text { Distance } \\
\text { from } \\
\text { Observer } \\
\text { (yards) }\end{array}$} & \multicolumn{3}{|c|}{$\begin{array}{c}\text { "Peenting" } \\
\text { First Detection Time }\end{array}$} & \multirow{2}{*}{$\begin{array}{l}\text { Outside } \\
\text { managed } \\
\text { patch? } \\
\text { check if } \\
\text { true }\end{array}$} & \multirow{2}{*}{$\begin{array}{c}\text { Range } \\
\text { Finder } \\
\text { Used? } \\
\text { check if } \\
\text { true }\end{array}$} \\
\hline & & $\begin{array}{l}0-2 \\
\text { mins }\end{array}$ & $\begin{array}{l}2-4 \\
\operatorname{mins}\end{array}$ & $\begin{array}{l}4-6 \\
\operatorname{mins}\end{array}$ & & \\
\hline 1 & & & & & $\square$ & $\square$ \\
\hline 2 & & & & & $\square$ & $\square$ \\
\hline 3 & & & & & $\square$ & $\square$ \\
\hline 4 & & & & & $\square$ & $\square$ \\
\hline 5 & & & & & $\square$ & $\square$ \\
\hline 6 & & & & & $\square$ & $\square$ \\
\hline $\begin{array}{c}\text { Total } \\
\text { AMWO }\end{array}$ & & & & & & \\
\hline
\end{tabular}

Use the diagram to help keep track of individual peenting male woodcock, 25 yard rings are shown.

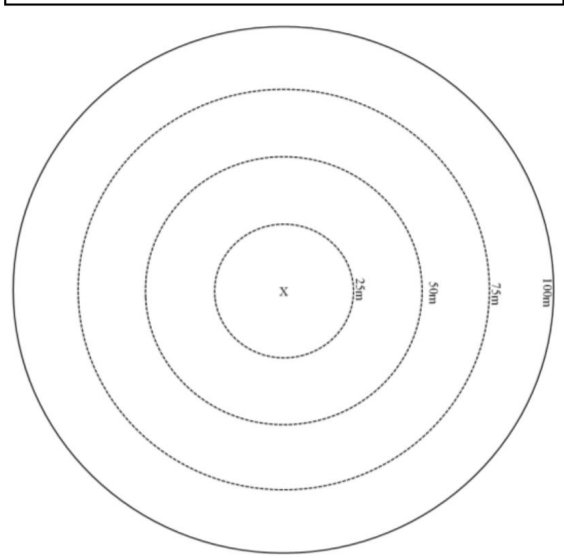

OPTIONAL: Other Nocturnal Bird Detections

\begin{tabular}{|l|c|c|c|c|c|c|}
\hline $\begin{array}{l}\text { Nocturnal Bird } \\
\text { Species }\end{array}$ & $\begin{array}{c}\text { Distance } \\
\text { from } \\
\text { Observer } \\
\text { (yards) }\end{array}$ & \begin{tabular}{l} 
First Detection Time \\
\cline { 5 - 7 }
\end{tabular} & $\begin{array}{c}0-2 \\
\text { mins }\end{array}$ & $\begin{array}{c}2-4 \\
\text { mins }\end{array}$ & $\begin{array}{c}\text { Outside } \\
\text { managed } \\
\text { mins } \\
\text { patch? } \\
\text { check if } \\
\text { true }\end{array}$ & $\begin{array}{c}\text { Range } \\
\text { Finder } \\
\text { Used? } \\
\text { check if } \\
\text { true }\end{array}$ \\
\hline \hline & & & & & $\square$ & $\square$ \\
\hline & & & & & $\square$ & $\square$ \\
\hline & & & & & $\square$ & $\square$ \\
\hline
\end{tabular}

Notes:

Remember that surveys begin at calculated start time and continue for no longer than 38 minutes each night. 